\title{
APLIKASI PENENTUAN JENIS PART OF SPEECH MENGGUNAKAN METODE N-GRAM DAN STRING MATCHING
}

\author{
${ }^{1}$ Nurzaenab dan ${ }^{2}$ Purnawansyah \\ 1nurzaenab16@yahoo.co.id, 2purnawansyah@gmail.com \\ ${ }^{12}$ Teknik Informatika, Fakultas IImu Komputer, Universitas Muslim Indonesia
}

\begin{abstract}
Abstrak
Bahasa Inggris merupakan bahasa ibu dalam skala internasional sebagai alat komunikasi antar negara. Bahasa Inggris memiliki aturan baik dalam hal pengucapan dan penulisan disebut Grammar yang membentuk pola-pola. Pola-pola tersebut tersusun oleh setiap kata yang memiliki bentuk-bentuk tersendiri yang disebut Parts Of Speech. Bentuk dalam Parts Of Speech terbagi dalam delapan bentuk yaitu Noun (kata benda), Pronoun (kata ganti), Verb (kata kerja), Adjective (kata sifat), Adverb (kata keterangan), Preposition (kata depan), Conjuction (kata penghubung), Interjection (kata seru). Tingkat ingatan manusia tentu berbeda-beda. Ingatan untuk membedakan kata-kata dan pembentukan pola kalimat dalam part of speech. Setiap kata akan ditentukan jenis part of speechnya, tergantung dari inputan user. Sedangkan pola kalimat akan di tentukan sesuai inputan user berdasarkan part of speech-nya. Perancangan dilakukan menggunakan metode uni-gram dan String Matching (Knuth Morris Pratt).
\end{abstract}

Kata kunci : Grammar, N-Gram, Part Of Speech, String Matching

(i) (2)

EY SA ILKOM Jurnal IImiah work is licensed under a CCA-SA 4.0 International License.

\section{Pendahuluan}

Bahasa Inggris merupakan bahasa ibu dalam skala internasional sebagai alat komunikasi antar negara. Bahasa Inggris memiliki aturan baik dalam hal pengucapan dan penulisan disebut Grammar yang membentuk pola-pola. Pola-pola tersebut tersusun oleh setiap kata yang memiliki bentuk-bentuk tersendiri yang disebut Parts Of Speech.

Bentuk dalam Parts Of Speech terbagi dalam delapan bentuk yaitu Noun (kata benda), Pronoun (kata ganti), Verb (kata kerja), Adjective (kata sifat), Adverb (kata keterangan), Preposition (kata depan), Conjuction (kata penghubung), Interjection (kata seru).

Tingkat ingatan manusia tentu berbeda-beda. Ingatan untuk membedakan kata-kata dan pembentukan pola kalimat dalam part of speech. Setiap kata akan ditentukan jenis part of speechnya, tergantung dari inputan user. Sedangkan pola kalimat akan di tentukan sesuai inputan user berdasarkan part of speech-nya Hal itu melatarbelakangi penulis untuk merancang sebuah aplikasi untuk menentukan kata-kata dan pola kalimat dalam bentuk Parts Of Speech. Metode yang digunakan adalah metode uni-gram dan String Matching (Knuth Morris Pratt).

Tujuan penelitian adalah menghasilkan aplikasi yang dapat mengklasifikasikan kata-kata dan pola kalimat kedalam bentuk Parts Of Speech menggunakan metode uni-gram dan String Matching (Knuth Morris Pratt). Penelitian ini memiliki beberapa batasan permasalahan yaitu: hanya menentukan kata-kata dan pola kalimat dalam bentuk Parts Of Speech.

\section{Landasan Teori}

\subsection{Part Of Speech}

Part Of Speech adalah sebuah pengklasifikasian kata sesuai dengan bentuk kata. Bentuk dalam Parts Of Speech terbagi dalam delapan bentuk yaitu Noun (kata benda), Pronoun (kata ganti), Verb (kata kerja), Adjective (kata sifat), Adverb (kata keterangan), Preposition (kata depan), Conjuction (kata penghubung), Interjection (kata seru).

\subsection{Metode String Matching Knuth Morris Pratt}

Algoritma Knuth Morris Pratt dikembangkan oleh D. E. Knuth, bersama-sama dengan J. H. Morris dan V. R. Pratt [1][2]. Dengan algoritma KMP waktu pencarian dalam pencocokan pattern dan teks dapat berkurang dikarenakan algoritma ini melakukan sejumlah pergeseran lebih jauh sesuai dengan informasi ketidakcocokan string antara teks dan pattern. 
Algoritma Knuth Morris Pratt melakukan pencarian string dari arah kiri ke kanan pada teks. Dengan membandingkan antara teks yang ada dengan teks yang ada pada basisdata.

\subsection{Metode Uni-Gram}

Metode Uni-gram adalah salah satu metode n-Gram yang digunakan untuk memprediksi suatu teks. Karakter yang diambil senilai satu karakter kemudian digunakan untuk dicocokkan dalam teks yang terdapat dalam database kata. Contoh: Computer. Pengambilan satu karakternya yaitu "C", "o", "m", "p", "u", "t", "e", "r".

Persamaan (1) menunjukkan proses penghitungan skor tiap passage yang dilakukan dengan menjumlahkan semua kemungkinan $\mathrm{x}$-gram yang cocok, dimana $\mathrm{x} \leq$ jumlah kata pada kueri pertanyaan $\mathrm{N}$-gram.

$$
\text { Sum }=\sum_{x=1}^{n} \sum_{y=1}^{n}(m * 1)
$$

Dengan $\mathrm{m}=1$ apabila cocok, dan $\mathrm{m}=0$ untuk selainnya. Untuk skor maksimum dari rumus uni-gram sum pada rumus (3), $m=1$ untuk semua nilai dari $x$ dan y. Jadi nilai maksimum dari semua kemungkinan uni-gram adalah $\left(n^{*}(n+1) / 2\right)$. Jadi skor yang diperoleh oleh tiap passage ditunjukkan oleh persamaan (2).

$$
\text { uni-Gram Score } \frac{n-\text { gram sum }}{=}
$$

\subsection{UML (Unified Modeling Language)}

Unified Modelling Language (UML) adalah sebuah bahasa pemodelan sistem dengan visualisasi, merancang dan mendokumentasikan sistem perangkat lunak.

\section{Metode}

\subsection{Algoritma Metode Uni-Gram dan String Matching Knuth Morris Pratt}

Aplikasi Penentuan Jenis Part Of Speech adalah aplikasi untuk menentukan kata dan kalimat yang termasuk dalam part of speech. Di bawah ini akan diuraikan algoritma implementasi metode ngram dan string matching (knuth morris pratt).

\subsubsection{Algoritma Penentuan Kata}

Berikut adalah algortima penentuan kata yang termasuk penentuan jenis part of speech.

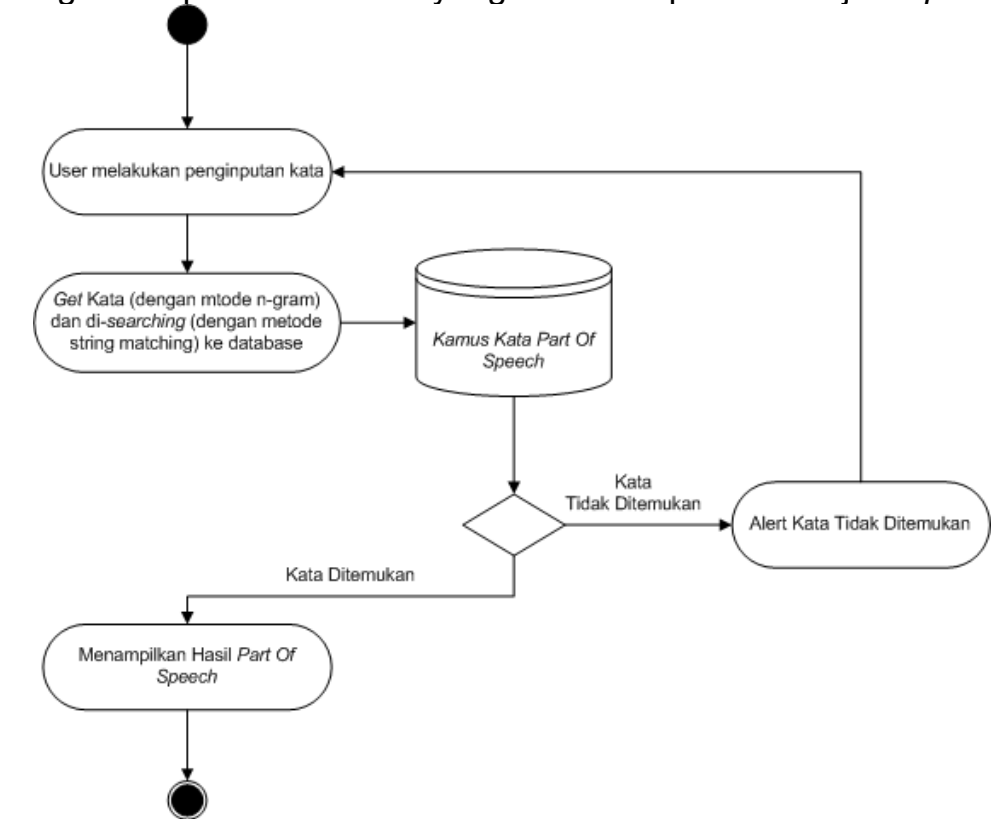

Gambar 1 Algoritma penentuan kata yang termasuk part of speech. 


\subsubsection{Algoritma Penentuan Kalimat}

Berikut adalah algortima penentuan kata yang termasuk penentuan jenis part of speech.

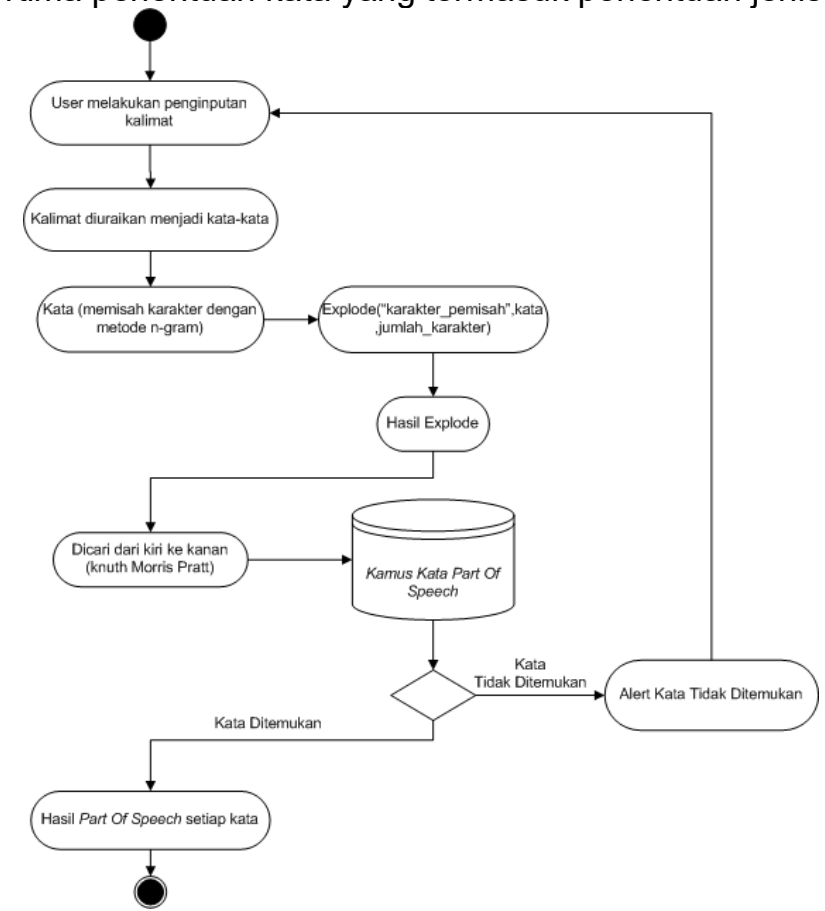

Gambar 2 Algoritma penentuan kalimat yang termasuk part of speech.

\subsubsection{Algoritma Penggunaan Metode Uni-Gram dan String Matching}

Metode yang digunakan untuk membangun aplikasi penentuan jenis part of speech adalah metode uni-gram dan knuth morris pratt. Pengambilan karakter yaitu menggunakan metode uni-gram sedangkan untuk pencarian karakter dan pencocokan karakter pada kamus kata menggunakan metode knuth morris pratt.

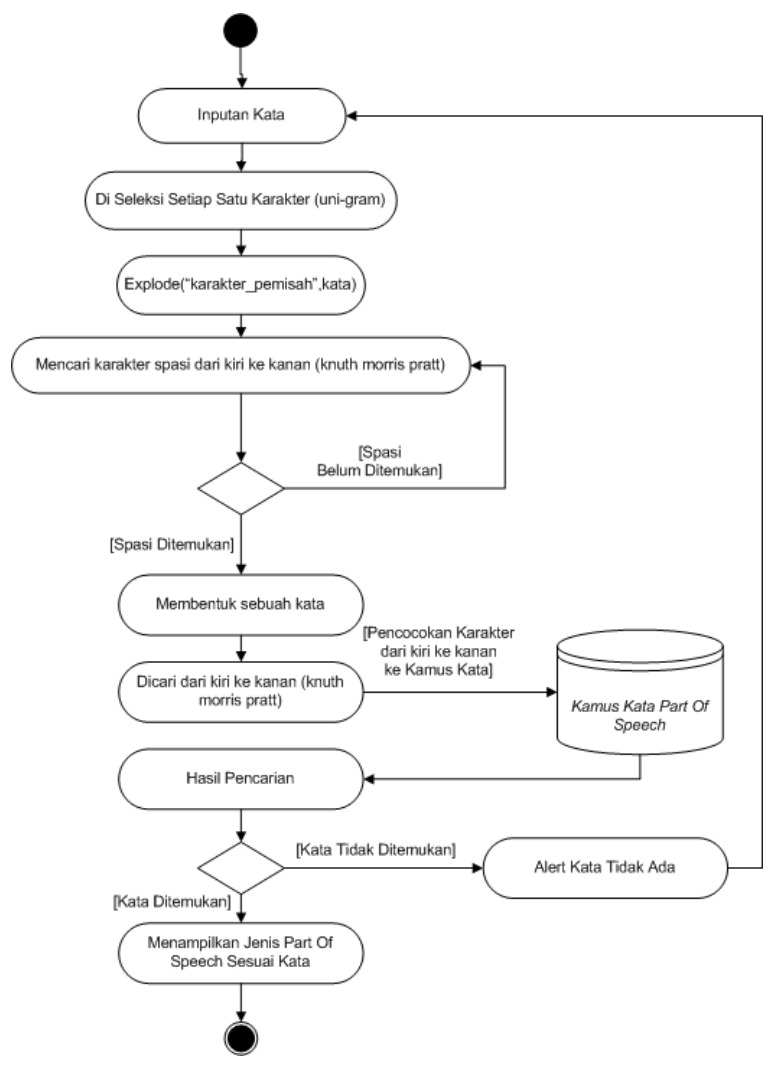

Gambar 3 Algoritma Penggunaan Metode Uni-gram dan Knut Morris Pratt. 


\section{Hasil}

Pada implementasi antar muka ini, menjelaskan tentang halaman utama pada aplikasi yang merupakan penghubung dengan sub-sub menu lainnya yang ada pada aplikasi. Berikut adalah penjelasan dari implementasi sistem aplikasi penentuan jenis part of speech berbasis web yang dijelaskan di bawah ini.

\subsection{Tampilan Menu Informasi}

Tampilan menu informasi menampilkan informasi untuk member yang belum mengetahui mengenai aplikasi.

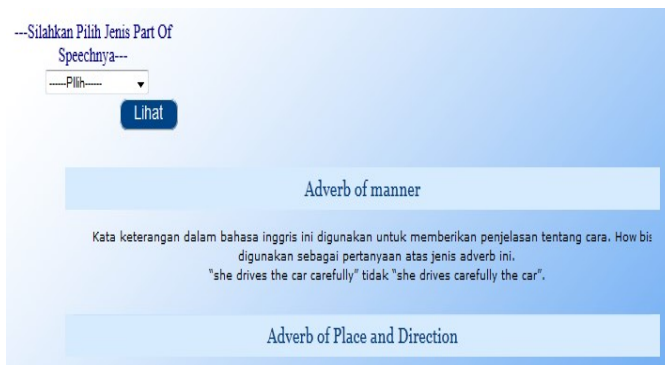

Gambar 4 Tampilan Menu Informasi

\subsection{Tampilan Penentuan kata}

Tampilan penentuan kata menjelaskan aktifitas member dalam menggunakan aplikasi. Member melakukan penginputan kata kemudian diproses oleh system dan menampilkan jenis part of speechnya.

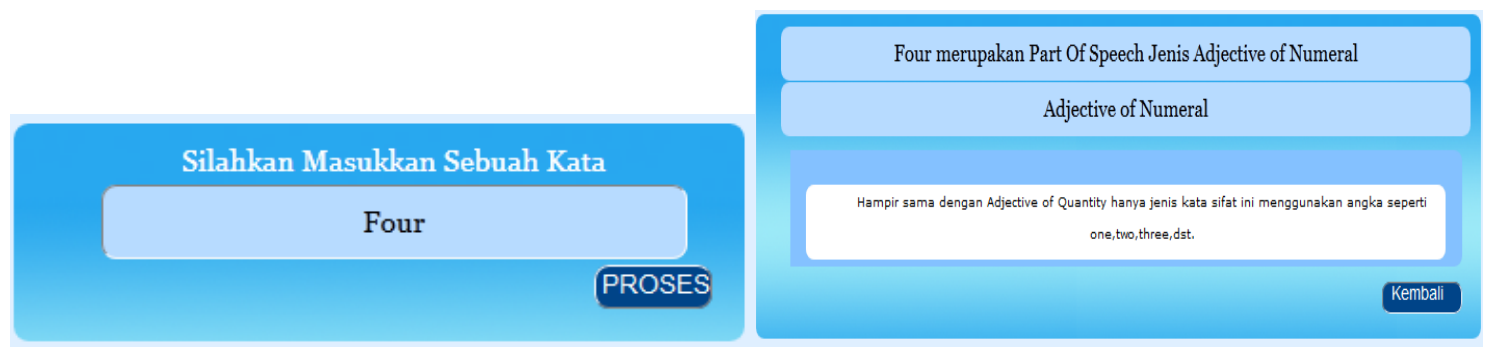

Gambar 5 Tampilan Penentuan Kata

\subsection{Tampilan Penentuan Kalimat}

Tampilan penentuan kalimat menjelaskan aktifitas member dalam menggunakan aplikasi. Member melakukan penginputan kalimat kemudian diproses oleh system dan menampilkan bentuk kalimat part of speech-nya

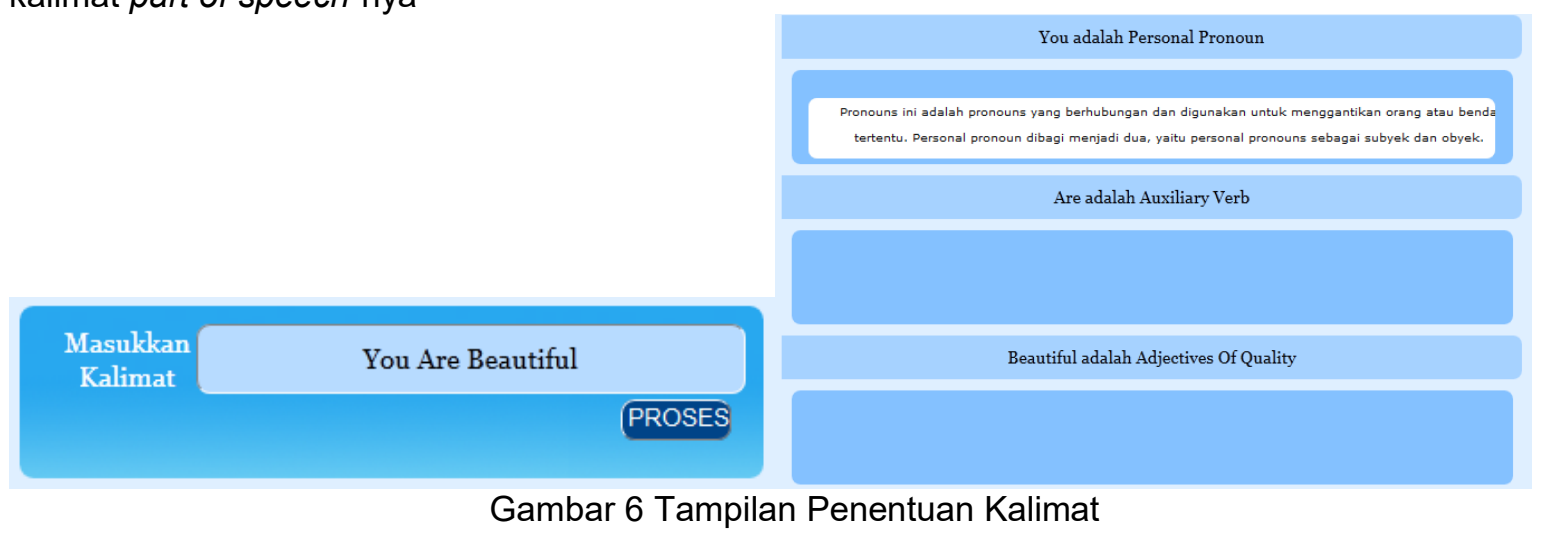




\section{Kesimpulan}

Berdasarkan hasil analisis perancangan dan pembangunan sistem, maka dapat diambil beberapa kesimpulan sebagai berikut:

1. Aplikasi Penentuan Jenis Part Of Speech adalah aplikasi untuk menentukan sebuah kata atau kata dalam kalimat yang termasuk dalam bentuk part of speech (Noun, Pronoun, Verb, Adverb, Preposition, Conjuntion, Adjective, Interjection).

2. Jalannya aplikasi dibangun dengan menggunakan metode N-gram (Uni-gram) dan String Matching (Knuth Morris pratt).

\section{Daftar Pustaka}

[1]. Tio Wibowo, Ardianto Wibowo, Rika Perdana Sari. 2012. Pembuatan Aplikasi Untuk Mendeteksi Kebenaran Perintah SQL Query Menggunakan Metode Knuth-Morris Pratt (KMP). Jurnal of Computer Science.

[2]. Wulan, Sri. 2011. Analisis Penerapan String Matching Dalam Komparasi Data Kepesertaan Jaminan Kesehatan Masyarakat (JAMKESMAS). Jakarta. 